\title{
Changes in pulmonary venous flow pattern during early neonatal life
}

Youtaro Agata, Satoshi Hiraishi, Koki Oguchi, Masahiko Nowatari, Kou Hiura, Kimio Yashiro, Takao Shimoda

\begin{abstract}
Objective-To investigate serial changes in the pattern of flow in the pulmonary vein during the early neonatal period. Methods-Pulsed Doppler echocardiography was used to measure flow in the right upper pulmonary vein in 26 normal newborn infants. Peak flow velocity during systole (S) and diastole (D) and flow velocity at indents between the systolic and diastolic fraction (O) and between the diastolic and systolic fraction (X) were measured 1, 4-8, 24, and 96 hours after birth. The heart rate and diameter of the ductus arteriosus were measured simultaneously.

Results-Continuous and phasic high flow velocity waveforms were seen 1 and 4-8 hours after birth. The mean (SD) peak flow velocities of $X, S, O$, and $D$ an hour after birth were $35.2(13.6) \mathrm{cm} / \mathrm{s}$, $73.1(23.1) \mathrm{cm} / \mathrm{s}, 58.5(20.5) \mathrm{cm} / \mathrm{s}$, and $81.5(19.2) \mathrm{cm} / \mathrm{s}$ respectively. There were significant decreases in $X, S, O$, and $D$ by 24 hours of age ( $p<0.01 v 1$ hour after birth) to $8 \cdot 1(10 \cdot 3) \mathrm{cm} / \mathrm{s}, 52 \cdot 8(18 \cdot 0) \mathrm{cm} / \mathrm{s}$, $38.6(14.5) \mathrm{cm} / \mathrm{s}$, and $54.4(11.2) \mathrm{cm} / \mathrm{s}$ respectively. These results indicate intermittent flow in the pulmonary vein, with flow stopping between diastole and systole. These flow velocities, $X, S, O$, and $D$, correlated well with the diameter of the ductus arteriosus $(r=0.80 v \mathrm{X}$, $r=0.62 v \mathrm{~S}, r=0.63 v \mathrm{O}, r=0.75 v \mathrm{D})$. Conclusion-This serial study showed changes in normal pulmonary vein flow patterns during the early neonatal period. The continuous and high flow velocity waveform that was seen immediately after birth resembled the pattern of pulmonary vein flow seen in congenital pulmonary stenosis and in cases of acute volume overload. This waveform may reflect a sudden increase in pulmonary circulatory volume with additional left to right shunting through the ductus arteriosus in relatively hypoplastic pulmonary veins.
\end{abstract}

(Br Heart F 1994;71:182-186)

Echocardiographic examination of abnormal pulmonary vein flow during the neonatal period is useful in the diagnosis of total anomalous pulmonary venous return, congenital pulmonary vein stenosis, and persis- tent pulmonary hypertension in cyanotic neonates. ${ }^{1-6}$ None the less, the normal pattern of pulmonary vein flow during the newborn period has not yet been established. It is believed that the considerable increase pulmonary blood volume and the rapid decline in pulmonary arterial pressure at birth are likely to influence the pulmonary venous flow pattern. A considerable left to right shunt through the ductus arteriosus immediately after birth adds to the much increased pulmonary circulatory volume. ${ }^{7}$

We used pulsed Doppler echocardiography to study serial changes in the pattern of pulmonary vein flow in healthy infants during the early neonatal period. In most infants the ductus arteriosus is closed or starting to close within 24 to 48 hours after birth. We studied the effect of ductal closure on the pulmonary venous flow. ${ }^{819}$

Because the tachypnoeic and periodic respiratory patterns of neonates may affect the pulmonary circulation we also examined the influence of respiration on the pattern of flow in the pulmonary vein.

\section{Patients and methods}

PATIENTS

Informed consent was obtained before delivery from each mother with an uncomplicated pregnancy. We studied 26 neonates 1 , 4-8, 24, and 96 hours after birth. Gestational age at birth, calculated from the first day of the last menstrual period, was 37-40 weeks (mean 38 weeks) and birth weight was 2310-3824 g (mean $3039 \mathrm{~g}$ ). The infants were normal at birth and were of an appropriate size. None showed any evidence of congenital heart disease or abnormality of any other organ system.

\section{EXAMINATION TECHNIQUE}

We used a Hewlett-Packard model 77025 A with 5.0 MHz transducers. Cross sectional real-time colour flow imaging was used to position the Doppler sample volume at the orifice of the right upper pulmonary vein. We used the apical four-chamber view to examine the right upper pulmonary vein. The angle of the Doppler sampling beam in relation to the direction of flow was estimated by an angle cursor on the sample line and the view was adjusted to $\leqslant 20^{\circ}$.

\section{DATA ANALYSIS}

We calculated mean values for five consecutive beats for (a) heart rate (in beats per 
minute), (b) peak flow velocities during ventricular systole $(\mathrm{S})$ and diastole $(\mathrm{D}),(c)$ and flow velocities at indents between the $S$ and $\mathrm{D}$ fractions $(\mathrm{O})$ and $\mathrm{D}$ and $\mathrm{S}$ fractions (X).

In eight infants we simultaneously recorded respiration at the time of pulmonary venous flow recordings. $S$ and $D$ were measured at end inspiration and end expiration respectively. To evaluate the effects of respiration we compared end inspiratory cycles with end expiratory cycles.

\section{DUCTUS ARTERIOSUS}

The inner diameter and shunt pattern of the ductus arteriosus were measured serially at the time of the pulmonary vein flow measurement. The size of the ductus arteriosus was determined from the inner diameter on cross sectional colour echocardiographic images. The inner diameter was measured at the narrowest portion of the ductal lumen in the parasternal long axis plane. ${ }^{8}$ The ductus arteriosus was considered to be closed when a colour image and shunt flow were no longer detected.

\section{STATISTICAL ANALYSIS}

The data were expressed as mean (SD). One way analysis of variance was used to evaluate the statistical differences. $p$ Values of $<0.05$ were regarded as significantly different.

\section{Results}

HEART RATE

The mean heart rate an hour after birth was 136 (12) beats/min. This had decreased significantly to 120 (22) beats/min 4-8 hours after birth $(p<0.01)$. Heart rate 24 hours after birth was 120 (19) beats/min. There was no significant change in heart rate between 24 hours and 96 hours after birth.

\section{PULMONARY VEIN FLOW PATTERN}

Figure 1 shows the characteristics of pulmonary vein flow at the serial examinations and fig 2 shows the serial changes for each measurement point. In adults and older children pulmonary vein flow has two phases and laminar pulsatile flows - the ventricular systolic phase and diastolic phase. The mean peak flow velocities of S and D (73.1 (23.1) $\mathrm{cm} / \mathrm{s}$ and $81.5(19.2) \mathrm{cm} / \mathrm{s}$ respectively) an hour after birth were considerably higher than previously reported data from older subjects. $X$ and $O$ were $35.2(13.6) \mathrm{cm} / \mathrm{s}$ and 58.5 $(20.5) \mathrm{cm} / \mathrm{s}$ respectively, reflecting the pattern of pulmonary vein flow which was continuous with a high flow waveform. Four to eight hours after birth each measurement was significantly lower $(p<0.01)$, however flow was still continuous. $\mathrm{X}, \mathrm{S}, \mathrm{O}$ and $\mathrm{D}$ were $22 \cdot 8(15.9) \mathrm{cm} / \mathrm{s}, 55 \cdot 8(18 \cdot 0) \mathrm{cm} / \mathrm{s}, 44 \cdot 7(15 \cdot 8)$ $\mathrm{cm} / \mathrm{s}$, and $61.5(19.0) \mathrm{cm} / \mathrm{s}$ respectively. Twenty four hours after birth $\mathrm{X}$ was $0 \mathrm{~cm} / \mathrm{s}$ in

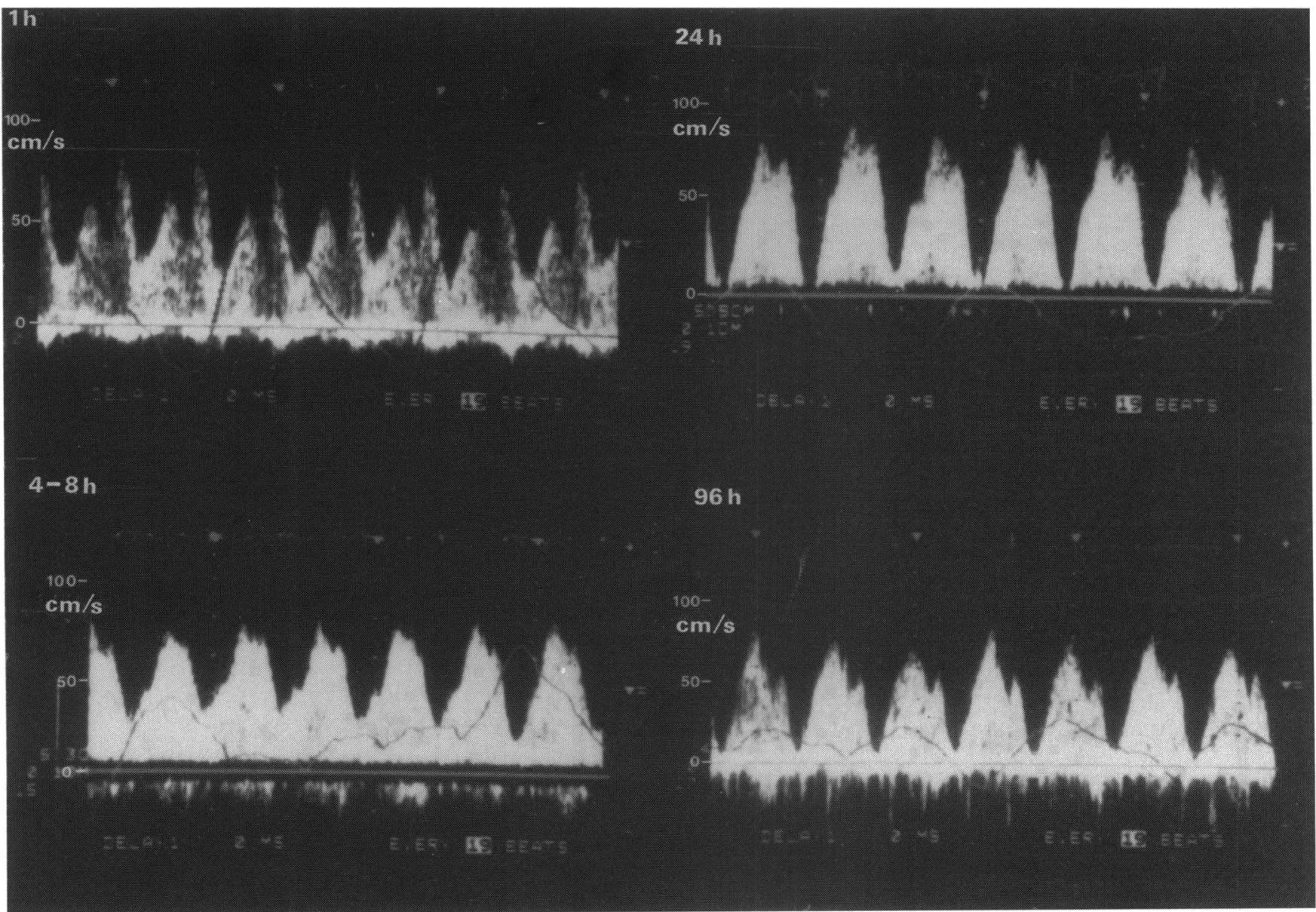

Figure 1 Pulmonary venous flow pattern obtained from the right upper pulmonary vein at 1, 4-8, 24, and 96 hours after birth. Measurements were made at peak flow velocity during ventricular systole $(S)$ and diastole $(D)$, and at flow velocity of indents between $S$ and $D(O)$ and $D$ and $S(X)$. At 1 and $4-8$ hours of age $X$ was over $20 \mathrm{~cm} / \mathrm{s}$, making the pulmonary venous flow pattern continuous. By contrast X at 24 and 96 hours after birth was near $0 \mathrm{~cm} / \mathrm{s}$ and the pulmonary venous flow pattern seemed intermittent. 


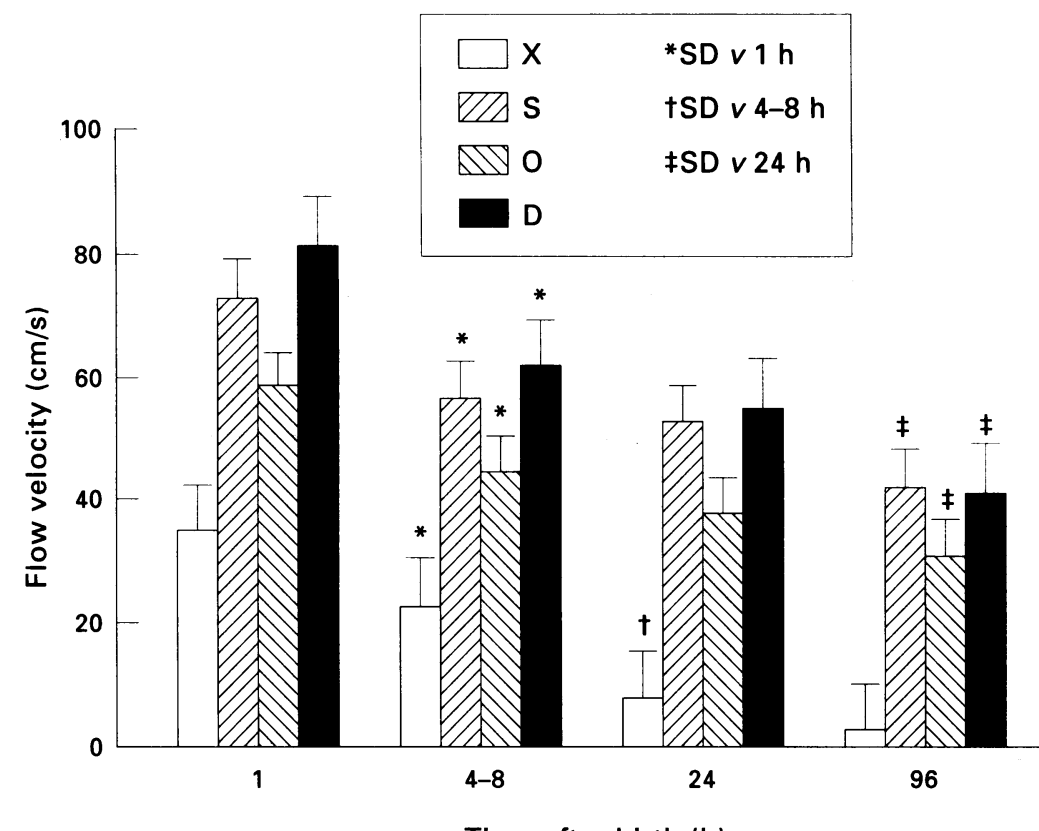

Time after birth (h)

Figure 2 Serial changes in mean (SD) flow velocity of $X, S, O$, and $D$. Each value was compared with the one immediately before it. Significant differences between groups: $p<0.01^{*}$ and $p<0.05^{* *}$. There was a considerable and significant decline in mean flow velocity in $X$ at 24 hours after birth.
$11(42 \%)$ infants, indicating, that the pattern had become intermittent with a phasic waveform. The mean flow velocities of $\mathrm{X}, \mathrm{S}, \mathrm{O}$ and $\mathrm{D}$ had fallen significantly $(\mathrm{p}<0.01 \mathrm{v} 1$ hour after birth) to $8.1(10.3) \mathrm{cm} / \mathrm{s}, 52.8$ $(18.0) \mathrm{cm} / \mathrm{s}, 38.6(14.5) \mathrm{cm} / \mathrm{s}$, and 54.4 $(11.2) \mathrm{cm} / \mathrm{s}$ respectively. Ninety six hours after birth values of $\mathrm{X}, \mathrm{S}, \mathrm{O}$, and $\mathrm{D}$ were $2 \cdot 8$ $(6.0) \mathrm{cm} / \mathrm{s}, 42.5(11.9) \mathrm{cm} / \mathrm{s}, 31.4(9.2) \mathrm{cm} / \mathrm{s}$, and $41.6(8.5) \mathrm{cm} / \mathrm{s}$ respectively $(\mathrm{p}<0.01 \mathrm{v}$ 1 hour after birth).

DUCTUS ARTERIOSUS SIZE

The diameter of the ductus arteriosus was 4.6 $(1 \cdot 0) \mathrm{mm} 1$ hour after birth. By 4-8 hours it had decreased significantly to $2.7(1.3) \mathrm{mm}$ $(p<0.01)$, none the less the ductus arteriosus was still open in all infants. At 24 hours of age the ductus arteriosus had closed in 18 infants $(69 \%)$ and was closing the others. The ductus arteriosus was closed in 24 infants (92\%) 96 hours after birth.

The diameter of the ductus arteriosus correlated well with flow velocity $(r=0.80$ for $\mathrm{X}, r=0.62$ for $\mathrm{S}, r=0.63$ for $\mathrm{O}$, and $r=0.75$ for $\mathrm{D})$.
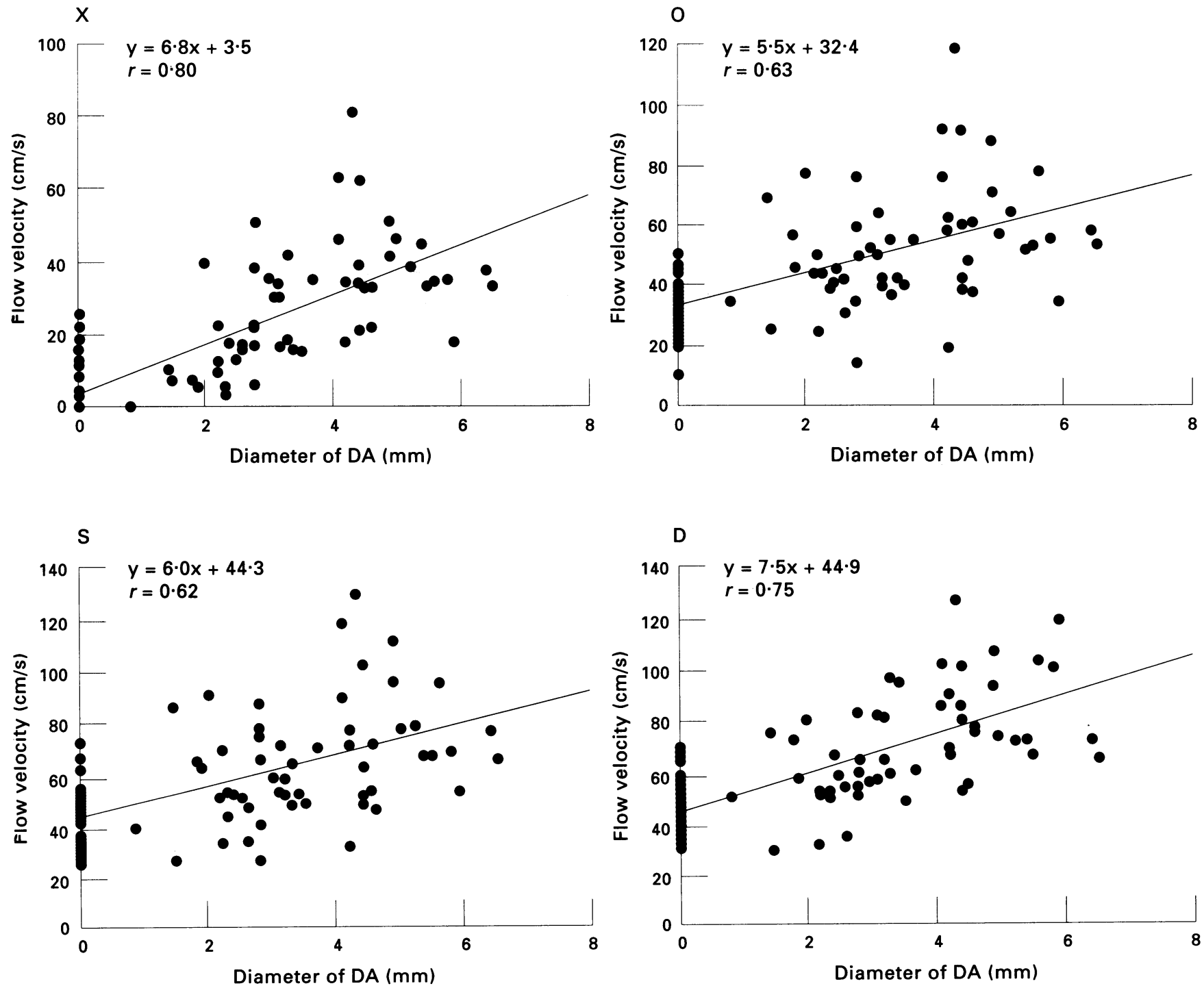

Figure 3 Correlation between changes in the diameter of the ductus arteriosus (DA) and changes in flow velocity at $X, S, O$, and $D$ measured in 23 patients 1, 4-8, 24, and 96 hours after birth. 
Influence of respiration on pulmonary venous flow (mean (SD)) in various age groups

\begin{tabular}{|c|c|c|c|c|c|c|}
\hline \multirow[b]{2}{*}{ Flow } & \multicolumn{2}{|l|}{$1 h$} & \multicolumn{2}{|l|}{$24 h$} & \multicolumn{2}{|l|}{$96 h$} \\
\hline & Inspiration & Expiration & Inspiration & Expiration & Inspiration & Expiration \\
\hline $\begin{array}{l}X \\
S \\
O \\
D \\
S / D\end{array}$ & $\begin{array}{c}44 \cdot 2(18 \cdot 7) \\
86.1(30.9) \\
70 \cdot 2(26 \cdot 6)^{\star} \\
92.2(17.6) \\
0.92(0.22)\end{array}$ & $\begin{array}{c}43.8(18.9) \\
84.8(29.1) \\
66.1(27.1) \\
88.7(15.6) \\
0.95(0.23)\end{array}$ & $\begin{array}{c}4.7(8.0) \\
61.8(20.1) \\
48.9(20.2) \\
63.7(12.2) \\
0.96(0.21)\end{array}$ & $\begin{array}{c}4.4(6.9) \\
59 \cdot 0(17 \cdot 1) \\
45 \cdot 2(18.9) \\
62.8(9.0) \\
0.94(0.21)\end{array}$ & $\begin{array}{c}3.6(8 \cdot 9) \\
52.7(22 \cdot 4) \\
35.6(11 \cdot 1) \\
49.4(9 \cdot 7) \\
1.03(0.24)\end{array}$ & $\begin{array}{c}3.1(7 \cdot 6) \\
50.7(21 \cdot 3) \\
34.3(10 \cdot 8) \\
47.7(10.5) \\
1.03(0.21)\end{array}$ \\
\hline
\end{tabular}

EFFECTS OF RESPIRATION

There was no significant change with respiration in S and D at 1, 24, and 96 hours after birth (table).

\section{Discussion}

We found that the pattern of flow in the pulmonary vein at 1 and 4-8 hours after birth was continuous with a high flow phasic waveform and without cessation of forward flow or reversed flow during atrial contraction. Doppler studies of the normal pattern of flow in adults and older children showed biphasic or triphasic flow with one or two forward phases during ventricular systole and one during ventricular diastole. ${ }^{6910}$ There was no forward flow from the pulmonary vein to the left atrium or backward and reversed flow from the left atrium into the pulmonary vein during atrial contraction so that the pattern of flow in the pulmonary vein was intermittent.

We also found that the mean peak flow velocities in infants were much higher than reported in adults and older children (40-50 $\mathrm{cm} / \mathrm{s}) . .^{911}$

\section{AETIOLOGY}

The aetiology of this continuous and high flow velocity waveform immediately after birth and the fall in the early neonatal period is unclear. Flow velocity might be expected to increase as pulmonary vascular resistance falls. In most of our infants the ductus had closed or was closing before they were 24 hours old. This is consistent with previous data. ${ }^{812}$ Left ventricular preload decreased and afterload increased with ductal closure. ${ }^{13}$ Others reported that an increase in preload, caused by acute volume infusion, significantly increased both systolic and diastolic pulmonary venous flow velocities. ${ }^{14}$ Though the influence of increased afterload is not fully understood, a tendency to prolongation of the deceleration time of diastolic pulmonary venous flow was reported. ${ }^{14}$ This tendency may play some part in fusing diastolic and systolic pulmonary venous flow. Thus it seems that patency of the ductus, associated with left to right shunting, is responsible for the continuous and high flow velocity waveform seen soon after birth. Studies in adults showed that left atrial pressure, created by contraction and relaxation of both the left atrium and left ventricle, is a major determinant of the pattern of pulmonary venous flow pattern..$^{1415}$ This implies that the pressure difference between the pulmonary vein and the left atrium influences the pattern pulmonary venous flow. There is little information on changes in pulmonary venous pressure. Studies in rabbits showed a difference in the longitudinal distribution of pulmonary vascular resistance. ${ }^{1617}$ In young rabbits there was a $75 \%$ pressure drop in arteries and pulmonary microvessels, in contrast to the $97 \%$ pressure drop in adults. ${ }^{1617}$ These data suggest that pressure differences between the pulmonary vein and left atrium are greater in young animals than adults. Persistent, relatively high pulmonary arterial pressure may exaggerate this difference immediately after birth. In addition pulmonary circulatory volume is increased by left to right shunting through the ductus arteriosus in relatively hypoplastic pulmonary vessels immediately after birth. These data indicate that the continuous and high flow pulmonary venous waveform after birth is influenced by the right side of the heart.

\section{RESPIRATION}

Respiration soon after birth seems to have little effect on the pulmonary venous flow pattern. It is widely accepted that right ventricular filling blood volume increases during inspiration and decreases during expiration. Appleton et al reported that in adults tricuspid E velocities were significantly higher during inspiration than during expiration, in contrast to mitral $\mathrm{E}$ velocities which declined during inspiration. ${ }^{18}$ They speculated that this discrepancy was partly accounted for by the pooling effect in the pulmonary vascular bed. In newborn infants tricuspid $\mathrm{E}$ velocities were significantly higher during inspiration than during expiration. ${ }^{19}$ There was no apparent change in mitral $\mathrm{E}$ velocity, however. ${ }^{19}$ The nature of this difference is still unclear, but the pooling effect in the pulmonary bed cannot be fully effective because the pulmonary blood vessels are somewhat hypoplastic immediately after birth. Newborn infants are tachypnoeic and tachycardic, so that the effect of respiration on pulmonary vein flow will be lessened. Our data are consistent with these data and previously reported speculations.

\section{CLINICAL IMPLICATION}

A continuous and high flow velocity waveform is also seen in patients with total anomalous pulmonary venous return associated with pulmonary obstruction and congenital pulmonary venous stenosis. ${ }^{1-5}$ It is not difficult to detect patients with total anomalous pulmonary venous return with pulmonary obstruction because the pulmonary flow waveform among such patients was continuous and over $2 \mathrm{~ms}$, which apparently was higher than among normal neonates. ${ }^{1320}$ Colour flow mapping is also useful for detecting pulmonary venous flow draining into the left atrium in neonates. ${ }^{21}$ By contrast it seems to be more difficult to distinguish between congenital pulmonary venous stenosis and normal neonates because the pulmonary venous velocity was less $(0 \cdot 7-1 \cdot 8$ $\mathrm{m} / \mathrm{s}$ ), and the waveform was continuous and 
phasic. $^{3-5}$ In addition colour flow mapping was less useful.

\section{LIMITATION}

When the heart rate is high the diastolic period of flow is shortened and it seems likely that the heart rate will influence pulmonary venous flow. Our cases with higher heart rates after 24 hours of age, however, showed an intermittent and lower phasic pulmonary flow velocity waveform, which seemed different from the pattern seen at 1 and 4-8 hours after birth. Moreover the correlation $(r<0.5)$ between heart rate and pulmonary venous flow was poor.

1 Smallhorn JF, Freedom RM. Pulsed Doppler echocardiography in the preoperative evaluation of total anomalous pulmonary venous connection. $\mathcal{F}$ Am Coll Cardiol 1986; 8:1413-20.

2 Kimball RK, Weiss RG, Meyer.RA, Daniels SR, Ryckman FC, Schwartz DC. Color flow mapping to document normal pulmonary venous return in neonates with persistent pulmonary hypertension being considered for extracorporeal membrane oxygenation. $\mathcal{f}$ Pediatr 1989; 114:433-7.

3 Smallhorn JF, Pauperio H, Benson L, Freedom RM, Rowe RD. Pulsed Doppler assessment of pulmonary vein obstruction. Am Heart f 1985;110:483-6.

4 Webber SA, Souza E, Patterson MWH. Pulsed wave and color Doppler findings in congenital pulmonary vein color Doppler findings in congenital
stenosis. Pediatr Cardiol 1992;13:1 12-5.

5 Samdarshi TE, Morrow WR, Helmcke FR, Nanda NC, Bargeron LM Jr, Pacifico AD. Assessment of pulmonary vargeron $L M$ Jr, Pacifico AD. Assessment of pulmonary vein stenosis by transesop

6 Smallhorn JF, Freedom RM, Olley PM. Pulsed Doppler echocardiographic assessment of extraparenchymal pulmonary vein flow. $\mathcal{F}$ Am Coll Cardiol 1987;9:573-9.

7 Drayton MR, Skidmore R. Ductus -arteriosus blood flow during forty-eight hours of life. Arch Dis Child 1987;62: $1030-4$.
8 Hiraishi S, Misawa H, Oguchi K, Kadoi N, Saito K, Fujino N, Hojo $M$, Horiguchi $Y$, Yashiro $K$. Twodimensional Doppler echocardiographic assessment of closure of the ductus arteriosus in normal newborn infants. F Pediatr 1987;111:755-60.

9 Kuecherer HF, Muhiudeen IA, Kusumoto FM, Lee E, Moulinier LE, Cahalan MK, Schiller NB. Estimation of mean left atrial pressure from transesophageal pulsed mean left atrial pressure from transesophageal pulsed Doppler echocardiography of
Circulation 1990;82:1127-39.

10 Keren G, Sherez J, Megidish R, Levitt B, Laniado S Pulmonary venous flow pattern-its relationship to carPulmonary venous flow pattern-its relationship to car-
diac dynamics. A pulsed Doppler echocardiographic diac dynamics. A pulsed Dopple

11 Mori K, Dohi T, Yamamoto Y. Pulsed Doppler echocardiographic analysis of pulmonary venous flow in norma children. $¥$ भpn Pediatr Cardiol 1988;4:216-24.

12 Agata $Y$, Hiraishi S, Oguchi K, Misawa H, Horiguchi Y, Fujino N, Yashiro $K$. Changes in left ventricular output from fetal to early neonatal life. $\mathcal{F}$ Pediatr $1991 ; 119$. 441-5.

13 Rudolph AM. Developmental considerations in neonatal failure. Hosp Pract 1985;15:53-70.

14 Nishimura RA, Abel MD, Hatle LK, Tajik AJ. Relation of pulmonary vein to mitral flow velocities by transesophageal Doppler echocardiography. Effect of different loading conditions. Circulation 1990;81:1488-97.

15 Hoit BD, Shao Y, Gabel M, Walsh RA. Influence of loading conditions and contractile state on pulmonary
venous flow: validation of Doppler velocimetry. venous flow: validation
Cinculation 1992;86:651-9.

16 Raj JU, Chen P, Navazo L. Micropuncture measuremen of lung microvascular pressure profile in 3- to 4- week old rabbits. Pediatr Res 1986;20:1107-11.

17 Raj JU, Bland RD, Lai-Fook SJ. Microvascular pressure measured by micropipettes in isolated edematous rabbi lungs. F Appl Physiol 1986;60:539-45.

18 Appleton CP, Hatle LK, Popp RL. Cardiac tamponade and pericardial effusion: respiratory variation in transvalvular flow velocities studied by Doppler echocardiography. F Am Coll Cardiol 1988;11:1020-30.

19 Riggs TW, Rodriguez R, Snider AR, Batton D, Pollock J Sharp EJ. Doppler echocardiographic evaluation of right and left ventricular diastolic function in normal and left ventricular diastolic function

20 Fogel MA, Chin AJ. Imaging of pulmonary venous pathway MA, Chin AJ. Imaging of pulmonary venous pathway obstruction in patients after the modified

21 Sreeram N, Walsh K. Diagnosis of total anomalous pulmonary venous drainage by Doppler color flow imaging. f Am Coll Cardiol 1992;19:1577-82. 